\title{
A Symbiotic Virus Facilitates Aphid Adaptation to Host Plants by Suppressing Jasmonic Acid Responses
}

\author{
Hong Lu, ${ }^{1}$ Junjie Zhu, ${ }^{1,2}$ Jinting Yu, ${ }^{1,2}$ Xiaofang Chen, ${ }^{1,2}$ Le Kang, ${ }^{1,2, \dagger}$ and Feng Cui ${ }^{1,2,+}$ \\ ${ }^{1}$ State Key Laboratory of Integrated Management of Pest Insects and Rodents, Institute of Zoology, Chinese Academy of \\ Sciences, Beijing 100101, China \\ ${ }^{2}$ University of Chinese Academy of Sciences, Beijing 100049, China
}

Accepted 10 June 2019.

\begin{abstract}
Symbiotic viruses exist in many insects; however, their functions in host insects are not well understood. In this study, we explored the role of acyrthosiphon pisum virus (APV) in the interaction of its host aphid Acyrthosiphon pisum with plants. APV is primarily located in aphid salivary glands and gut and propagated in the insect. APV is horizontally transmitted to host plants during aphid feeding, but the virus does not replicate in the host plant. When the pea host race of aphids colonized two low-fitness plants, Medicago truncatula and Vicia villosa, the virus titers in both the aphids and plants significantly increased. Furthermore, APV infection strongly promoted the survival rate of the pea host race on $V$. villosa. Transcriptomic analysis showed that only $0.85 \%$ of aphid genes responded to APV infection when aphids fed on $V$. villosa, with a fold change in transcript levels of no more than fourfold. The improved survival due to APV infection was apparently related to the inhibitory effect of the virus on levels of phytohormone jasmonic acid (JA) and JA-isoleucine. Our data suggest a benefit of the symbiotic virus to its aphid host and demonstrate a novel case of symbiotic virus-mediated threespecies interaction.
\end{abstract}

Keywords: acyrthosiphon pisum virus, horizontal transmission, host adaptation, pea aphid, phytohormone, symbiotic virus

More than 5,000 aphid species are known, many of which are pests that result in significant economic losses in a wide range of crops worldwide (Blackman and Eastop 2000). Aphids possess several types of symbiotic microorganisms, particularly symbiotic bacteria and viruses. Symbiotic bacteria impact their aphid hosts in many ways, including nutrient assimilation, natural enemy avoidance, heat tolerance, and body color (Douglas 2013; Montllor et al. 2002; Scarborough et al. 2005; Tsuchida et al.

${ }^{\dagger}$ Corresponding authors: F. Cui; cuif@ioz.ac.cn and

L. Kang; lkang@ioz.ac.cn

Funding: This work was supported by the Strategic Priority Research Program of the Chinese Academy of Sciences (number XDB11040200) and the Natural Science Foundation of China (number 31772162). The funders had no role in the study design, data collection and analysis, decision to publish, or preparation of the manuscript.

*The $\boldsymbol{e}$-Xtra logo stands for "electronic extra" and indicates that five supplementary tables are published online.

The author(s) declare no conflict of interest.

๑) 2020 The American Phytopathological Society
2010; Vorburger 2014). However, only a handful of aphid symbiotic viruses have been characterized to date, including six RNA viruses, acyrthosiphon pisum virus (APV) (van der Wilk et al. 1997), rhopalosiphum padi virus (Moon et al. 1998), brevicoryne brassicae virus (Ryabov 2007), rosy apple aphid virus (Ryabov et al. 2009), aphis glycines virus 2 (Liu et al. 2016), and macrosiphum euphorbiae virus 1 (Teixeira et al. 2016), and two DNA viruses, myzus persicae densovirus (van Munster et al. 2003a) and dysaphis plantaginea densovirus (Ryabov et al. 2009). Moreover, the effects of symbiotic viruses on their host aphids and the mechanisms involved remain largely unknown.

Symbiotic relationships are not always mutually beneficial; such a relationship can be mutualism and depend on whether the benefits outweigh the costs. Negative effects of dysaphis plantaginea densovirus on development or fecundity have been reported for the rosy apple aphid (Ryabov et al. 2009), of myzus persicae densovirus for the green peach aphid (van Munster et al. 2003b), of rhopalosiphum padi virus for the wheat aphid (Ban et al. 2008), and of APV for the pea aphid (van den Heuvel et al. 1997). In contrast, benefits of these symbiotic viruses for their aphid hosts have not been well-explored. An example of such a benefit was observed between the rosy apple aphid, rosy apple aphid virus, and dysaphis plantaginea densovirus (Ryabov et al. 2009), whereby dysaphis plantaginea densovirus induces wing development and increases dispersal of the host and the virus and the presence of rosy apple aphid virus rescues the loss of host fecundity caused by dysaphis plantaginea densovirus.

Horizontal transmission is a prevailing characteristic of aphid symbiotic viruses, such as rhopalosiphum padi virus, myzus persicae densovirus, dysaphis plantaginea densovirus, rosy apple aphid virus, and macrosiphum euphorbiae virus 1 (Gildow and D'Arcy 1990; Ryabov et al. 2009; Teixeira et al. 2016; van Munster et al. 2003b). For horizontal transmission of symbiotic viruses to occur, the viruses must be located in the salivary glands of the aphids, and these viruses are transferred to plants via injection with aphid saliva when the host aphid feeds on plants. Once injected, symbiotic viruses function as effectors and may exert certain influences on plants, such as regulating the aphid-plant interaction. Plant hormone signaling plays a key role in this interaction. Jasmonic acid (JA) confers a more effective defense against insects than salicylic acid (SA), though SA does increase the resistance of plants to biotrophic pathogens (Giordanengo et al. 2010).

In previous work, we sequenced the salivary gland transcriptomes of a pea host race of the pea aphid Acyrthosiphon pisum living on a series of host plants, namely, Vicia faba, Medicago truncatula, Vicia villosa, and Medicago sativa, with high to low fitness (Lu et al. 2016). As many as $29 \%$ of the 
reads from the salivary gland transcriptomes mapped to the genome of APV, a picorna-like, positive-sense, single-stranded RNA virus. This 10-kb RNA genome contains two open reading frames, encoding helicase, protease, RNA-dependent RNA polymerase, and capsid protein (CP) (van der Wilk et al. 1997). APV is predominantly present in the epithelial cells of the digestive tract of the aphid (van den Heuvel et al. 1997) but also exists in the salivary gland.

Considering the existence of APV in the salivary glands of the pea aphid, we hypothesize that APV would be transmitted horizontally to plants and would regulate the interaction of aphids and plants. To test this hypothesis, we compared the performance of pea aphids on two host plants with or without APV infection and assessed variation in the virus load of aphids and plants after the aphids had adapted to the different host plants. Possible molecular mechanisms for the effect of APV on the interactions between aphids and plants were explored by evaluating gene expression variations in aphids confronted with APV infection and phytohormone variations in plants infested with APV-infected or APV-free aphids.

\section{RESULTS}

Tissue distribution and propagation of APV in pea aphids.

Among the six salivary gland transcriptomes of the pea aphids sequenced previously (Lu et al. 2016), 23 to 29\% of RNAseq reads were mapped to the APV genome (Supplementary
Table S1), suggesting that APV was abundant in the salivary glands of these aphids. The assembled APV genome sequences from the six salivary gland samples show $94 \%$ identity to the published sequence, with identities over $99 \%$ among the six samples. APV particles were extracted from the V. faba colony and were observed by electron microscopy. The virus particles are isometric in shape and approximately $33.3 \pm 0.9 \mathrm{~nm}$ in diameter (Fig. 1A).

To clarify the distribution of APV in the pea aphid, the RNA levels of viral CP in the salivary glands, brains, ovaries, and guts were quantified using reverse transcription-quantitative PCR (RT-qPCR). The results showed that APV was primarily located in the salivary glands and gut but was almost undetectable in the ovaries (Fig. 1B). The gut is usually the site of virus propagation, and whether a symbiotic virus is able to replicate in its host is an important characteristic. We evaluated the level of APV replication in the pea aphid. Virus-free aphids were inoculated with APV through feeding on an artificial diet containing an APV crude preparation from APV-infected aphids or plants for $12 \mathrm{~h}$. The RNA level of viral CP was measured at $0.5,1,2$, and 3 days after inoculation (dai). The RNA level of CP dramatically increased from 2 or 3 dai, suggesting that APV had propagated in the pea aphid (Fig. 1C and D).

\section{Vertical and horizontal transmission of APV.}

The small quantity of APV in the ovaries of the pea aphid suggested a low rate of vertical transmission. To verify whether
A

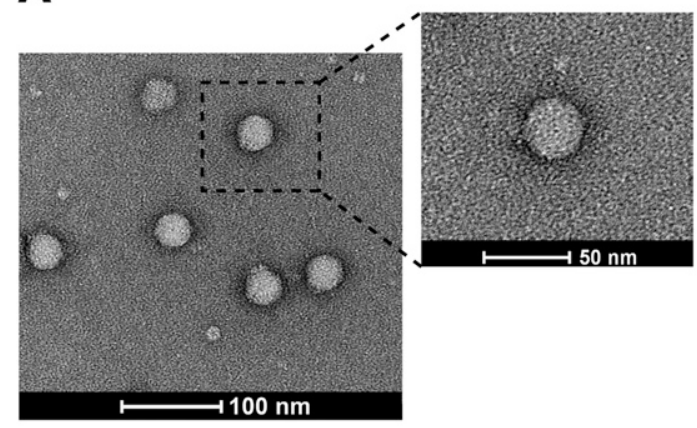

B

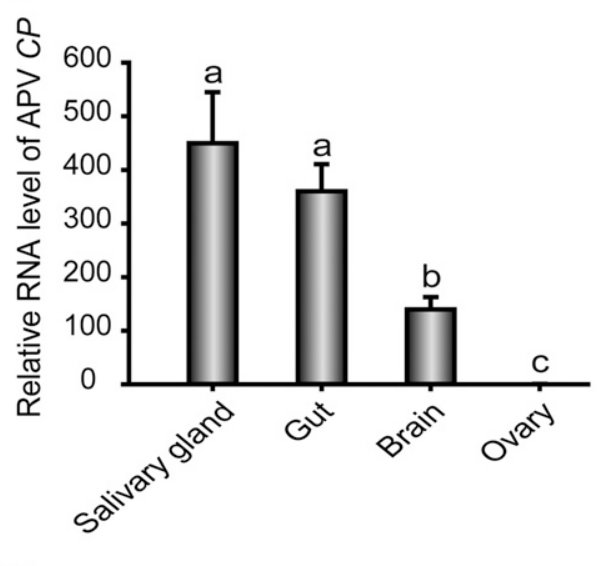

D

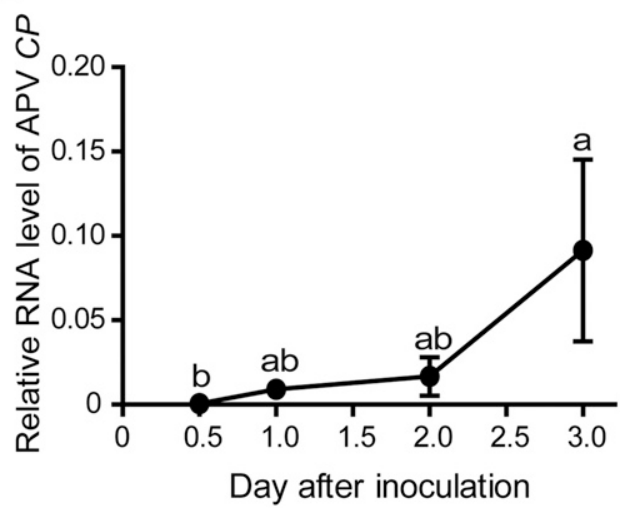

Fig. 1. Tissue distribution and propagation of acyrthosiphon pisum virus (APV) in pea aphids. A, Electron micrograph of APV particles extracted from the Vicia faba colony and stained with $2 \%$ uranyl acetate. B, Tissue distribution of APV in aphids by quantification of the relative RNA levels of viral capsid protein (CP) to those of aphid ribosomal protein L27, using reverse transcription-quantitative PCR (RT-qPCR). Six biological replicates were prepared. Values are expressed as the mean \pm standard error. Different letters indicate significant differences at $P<0.05$. C and $\mathbf{D}$, Propagation of APV in aphids when virus-free aphids were inoculated with virions from APV-infected aphids and plants, respectively. The relative RNA levels of viral CP to those of aphid ribosomal protein L27 were measured using RT-qPCR at different days after viral inoculation. At least four biological replicates were prepared. Values are expressed as the mean \pm standard error. Different letters indicate significant differences at $P<0.05$. 
APV is vertically transmitted from adults to offspring, progeny from 15 APV-infected adult aphids were collected before contact with plants and were tested individually for the presence of APV. Only 33\% of the progeny (17 of 52) were APV positive (Fig. 2A). Therefore, the vertical transmission rate of APV in the pea aphid was low.

Horizontal transmission of APV from aphids to plants was also investigated because of the high abundance of APV in salivary glands. APV-infected aphids were allowed to feed on $V$. faba for $48 \mathrm{~h}$, and the RNA level of CP in plants was measured at 1, 3,5, and 7 dai. No significant increase in virus load in the plants was detected over time; in fact, a decreasing trend was observed (Fig. 2B), indicating that APV did not replicate in plants but that the virus remained in the plants for at least 7 days. When $V$. faba plants were fed upon by APV-infected aphids for $1,3,5$, or 7 days, the RNA level of CP in plants
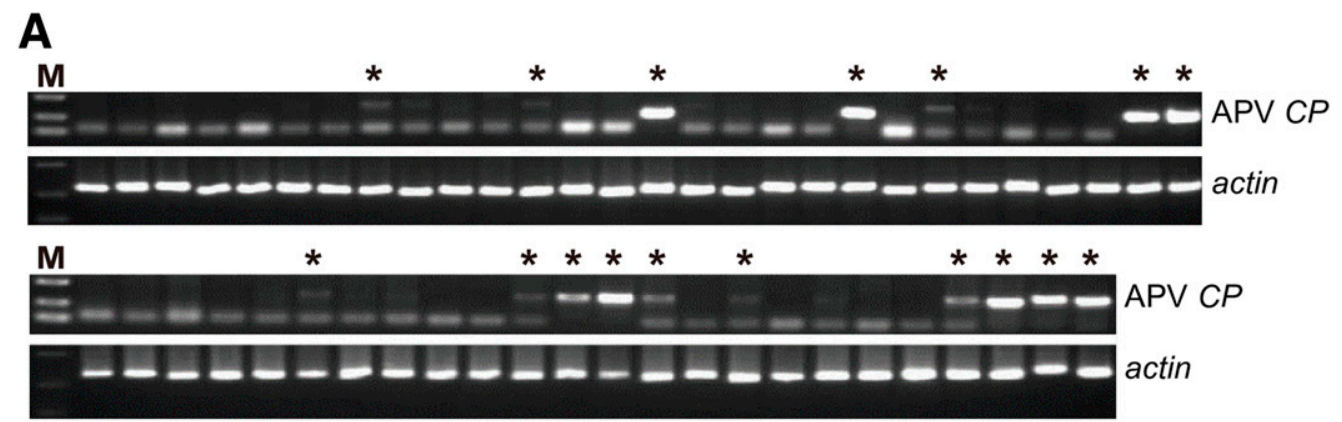

B

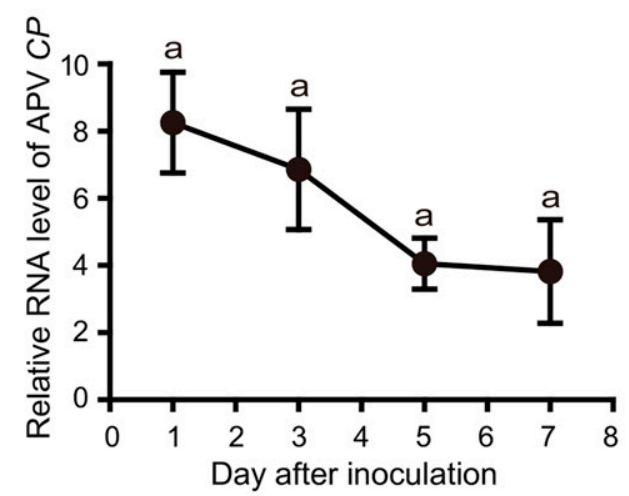

D

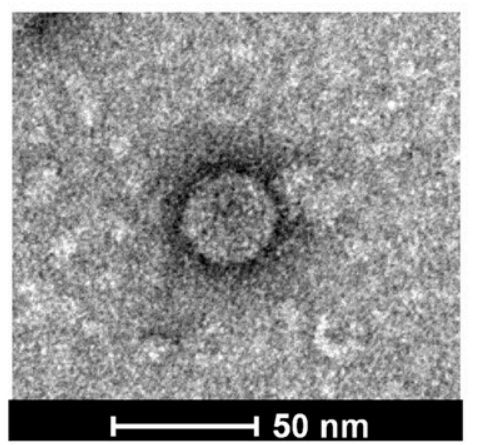

C

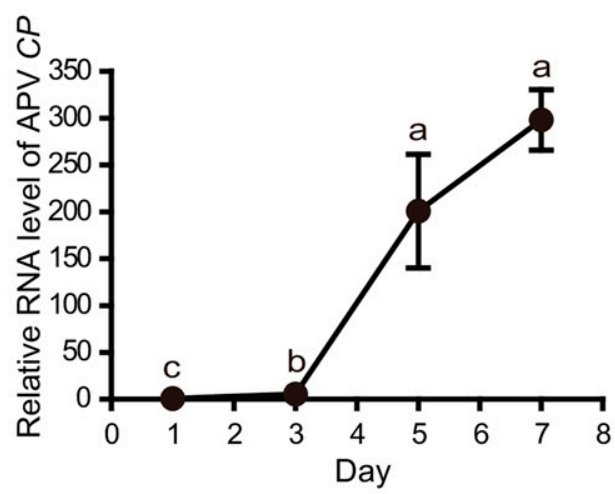

$\mathbf{E}$

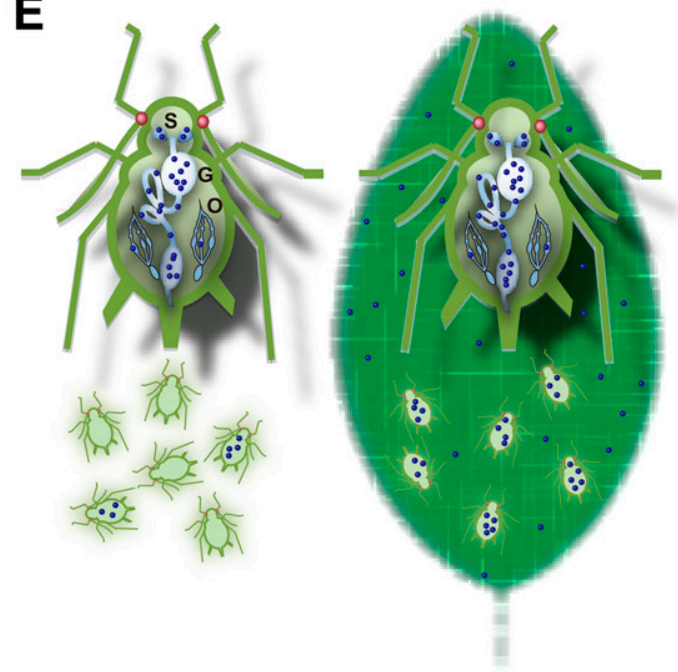

Fig. 2. Vertical and horizontal transmission of acyrthosiphon pisum virus (APV). A, Vertical transmission of APV. The RNA levels of APV capsid protein (CP) in 52 progeny from 15 APV-infected adult aphids of the Vicia faba colony were measured by reverse transcription PCR (RT-PCR) and gel imaging. Aphid actin was used as the internal control. $\mathrm{M}=$ marker. The black stars represent APV-positive individuals. B, APV replication in plants. The APV-infected V. faba colony was placed on $V$. faba leaves to feed for $48 \mathrm{~h}$ and was then removed from the leaves. The relative RNA levels of CP to those of $V$. faba actin were measured in $V$. faba on days 1, 3,5, and 7, using reverse transcription-quantitative PCR (RT-qPCR). Values are expressed as the mean \pm standard error (SE). At least six biological replicates were prepared. The same letters indicate no significant differences at $P<0.05$. C, Horizontal transmission of APV. The APV-infected $V$. faba colony was placed on $V$. faba leaves to feed for $1,3,5$, or 7 days and the leaves were collected for quantification of the relative RNA levels of APV CP to those of $V$. faba actin, using RT-qPCR. Values are expressed as the mean \pm SE. At least six biological replicates were prepared. Different letters indicate significant differences at $P<0.05$. D, Electron micrograph of APV particles extracted from virus-infected $V$. faba and stained with $2 \%$ uranyl acetate. E, The model diagram shows the vertical and horizontal transmission modes of APV. The blue dots represent APV particles. S, G, and O = salivary gland, gut, and ovary, respectively. 
increased greatly with the aphid feeding time, particularly after 3 days (Fig. 2C). As APV particles were also observed by electron microscopy after extraction from infected $V$. faba (Fig. 2D), the increase in virus load in the plants was due to horizontal transmission of APV from aphids. Furthermore, horizontal transmission led to all nymphs produced on these plants being infected with APV (Fig. 2E).

\section{Variation in APV load in aphids and plants} during aphid adaptation to different plants.

We next sought to determine whether the APV load in aphids varies when the aphids adapt to different host plants. The pea host race of pea aphids exhibits the highest fitness on $V$. faba, followed by M. truncatula and V. villosa (Lu et al. 2016). We compared the APV load in three aphid colonies raised on $V$. faba, M. truncatula, and V. villosa by quantifying the level of APV CP RNA; the latter two colonies were derived from the $V$. faba colony and acclimated on M. truncatula or $V$. villosa for six months. Compared with the $V$. faba colony, the $M$. truncatula and $V$. villosa colonies contained more APV, i.e., 2.1- and 2.7-fold more, respectively (Fig. 3A). Furthermore, when the three colonies fed on $V$. faba leaves, more APV was detected in the leaves fed on by the M. truncatula or $V$. villosa colony than in leaves fed on by the $V$. faba colony (Fig. 3B). These data show that more APV was produced in aphids and horizontally transmitted to plants when the pea aphids adapted to low-fitness host plants.

\section{Effects of APV on the adaptation of aphids to low-fitness host plants.}

To explore whether APV plays a role in the adaptation of aphids to low-fitness host plants, the reproduction and survival rates of $\mathrm{APV}$-infected and $\mathrm{APV}$-free aphids were compared on the high-fitness host plant $V$. faba and the low-fitness host plant $V$. villosa. The survival rate of aphids on $V$. faba was not affected by the presence of APV, whereas the reproductive rate of APV-infected aphids was significantly lower than that of APVfree aphids (Fig. 3C). On V. villosa, APV-infected aphids had a high survival rate, $85 \%$ after 12 days, whereas the survival rate of APV-free aphids declined with time and reached $62 \%$ after 12 days (Fig. 3D). Although no difference in the reproductive rates of APV-free and APV-infected aphids was observed when feeding on $V$. villosa, the rates were lower than those of aphids feeding on $V$. faba (Fig. 3D). These results demonstrate that APV was beneficial for the survival of pea aphids on a lowfitness host plant.

\section{Molecular response of aphids to APV infection.}

A benefit of APV for aphid survival on a low-fitness host plant would likely be derived from either a direct influence on the aphids or an indirect effect on the aphids via the plants. To clarify this question, the molecular response of pea aphids to APV infection was investigated by comparing the transcriptomes of APV-free and APV-infected pea aphids living on $V$. villosa. Three replicates from each group were sequenced, and the Q30 score of each sample was approximately 90\% (Supplementary Table S2). Correlation cluster analysis indicated that the gene transcriptional profiles of the three replicates from each group were consistent (Fig. 4A).

Among the 21,725 genes for which we found transcripts, only $184(0.85 \%)$ exhibited differential expression between the APV-free and APV-infected pea aphids with a threshold of fold change higher than 2 and an adjusted $P$-value lower than 0.01 (Fig. 4B). The highest fold change was fourfold. Compared with APV-free aphids, 14 genes were upregulated (Supplementary Table S3) and 170 genes were downregulated (Supplementary Table S4) in APV-infected aphids. Two detoxification enzyme genes, cytochrome P450 4C1 and UDPglucuronosyltransferase $2 \mathrm{C} 1$, and two glycogen metabolism related genes, facilitated trehalose transporter Tret1 and glucosidase, were upregulated. The enriched Gene Ontology (GO) term for the 170 downregulated genes was found to be structural constituent of cuticle (GO: 0042302), containing $16 \mathrm{cu}-$ ticular protein genes (Fig. 4C).

\section{Effects of APV on aphid feeding behavior.}

To evaluate whether APV affects aphid feeding behavior on a low-fitness host plant, the electrical penetration graph (EPG) technique was employed to characterize the feeding behavior of APV-free and APV-infected V. faba colonies on V. villosa. Compared with APV-free aphids, APV-infected aphids spent less time in nonprobing (np) and probing individual plant cells (C) waveforms and more time in overcoming the derailed stylet mechanics (F) waveform. Conversely, no significant variation in the time spent in feeding stages, i.e., watery salivation (E1), passive ingestion (E2), and drinking water from xylem $(\mathrm{G})$, was observed (Fig. 5). Thus, APV had a marginal effect on the feeding behavior of aphids transferred to $V$. villosa.

\section{Regulation of defense phytohormones by APV.}

Levels of the defense phytohormones JA, JA-isoleucine (JAIle), and SA in $V$. villosa and $V$. faba were measured and compared after infestation by an APV-infected or APV-free $V$. faba colony and without aphid infestation. The levels of JA and JA-Ile in $V$. villos $a$ after 1 day of feeding by APV-infected aphids decreased 70 to $80 \%$ compared with those in intact plants and decreased 85 to $90 \%$ compared with those in the plants fed on by APV-free aphids (Fig. 6A). After 2 days, the amounts of JA and JA-Ile in $V$. villosa fed on by APV-infected aphids decreased 60 to $70 \%$ compared with those in the other two groups (Fig. 6A). In addition, the level of SA significantly increased in $V$. villosa after being fed on by APV-infected aphids for 1 day but no further change was observed after 2 days (Fig. 6A).

In contrast, feeding by APV-infected or APV-free aphids did not significantly alter the amounts of JA and JA-Ile in the optimal host $V$. faba (Fig. 6B). Indeed, a significant decrease in the levels of JA and JA-Ile in $V$. faba was only observed after being fed on by APV-infected aphids for 2 days when compared with those in plants fed on by APV-free aphids (Fig. 6B). Nonetheless, the amount of SA in $V$. faba increased dramatically after feeding by APV-infected aphids for 2 days (Fig. 6B). In fact, the contents of JA and JA-Ile in V. villosa were much higher than those in $V$. faba, from two- to sevenfold of the latter. This might account for the low fitness of $V$. villos $a$ with regard to the pea host race of pea aphids.

These results demonstrate that APV lowered the level of JA to facilitate aphid survival on low-fitness plants.

\section{DISCUSSION}

Symbiotic viruses are present in many insects, but their physiological effects on host insects are rarely reported. Since APV was identified in pea aphids in 1997, the only demonstrated effect of the virus has been a negative impact on the growth of infected aphids (van den Heuvel et al. 1997). In this study, we discovered a benefit of APV in the host aphid after the virus was transmitted horizontally to the aphid's host plants. Indeed, APV facilitated host aphid adaptation to unsuitable plants by modifying the phytohormone defense response. Effectors are defined as proteins and small molecules of plant pathogens that are secreted to different cellular compartments of their hosts and alter host-cell structure and function. These alterations either facilitate infection or trigger defense 
responses or both (Hogenhout et al. 2009). Symbiotic viruses such as APV can be considered to be aphid effectors because of the virus's secretion by aphids and because of involvement of the virus in interactions between aphids and host plants. Our findings thus demonstrate a novel case of symbiotic virusmediated three-species interaction.

Host choice plays a critical role in the process of host range evolution, specialization, and ecological speciation (Ferrari
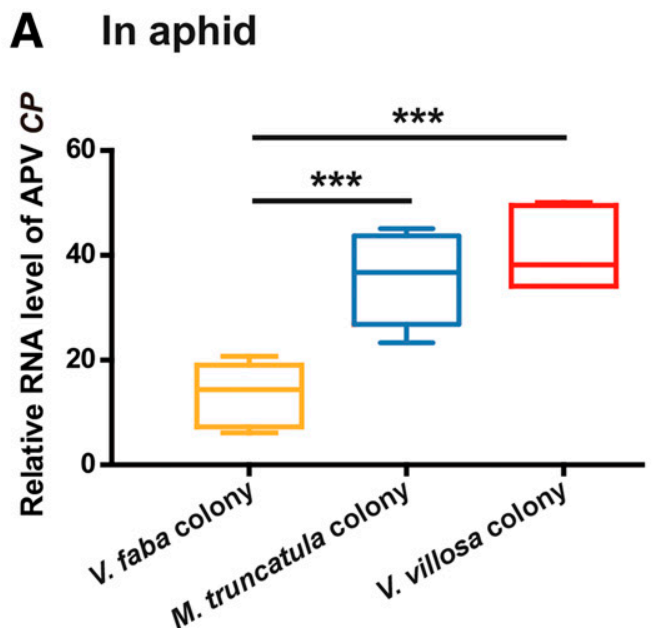

C On Vicia faba

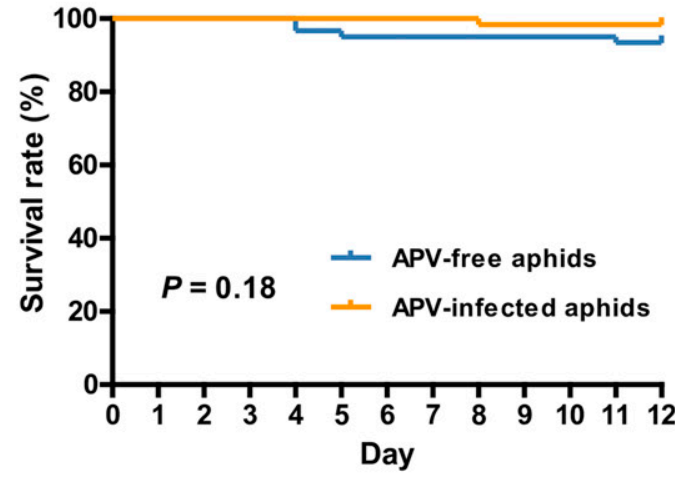

D On Vicia villosa

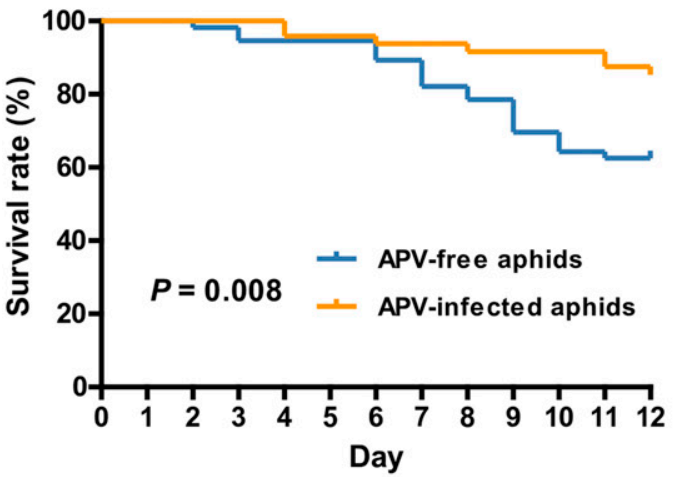

et al. 2006). For example, by shifting and adapting to new plants, at least 11 well-distinguished sympatric host races or biotypes of the pea aphid have been generated in Western Europe (Peccoud et al. 2009). The ecological benefits of host alteration include nutrition complementarity, escape from natural enemies and plant defenses, and superior sites for depositing overwintering eggs (Moran 1992). Some salivary proteins and metabolic enzymes, especially cytochrome P450s,

\section{B In plant}
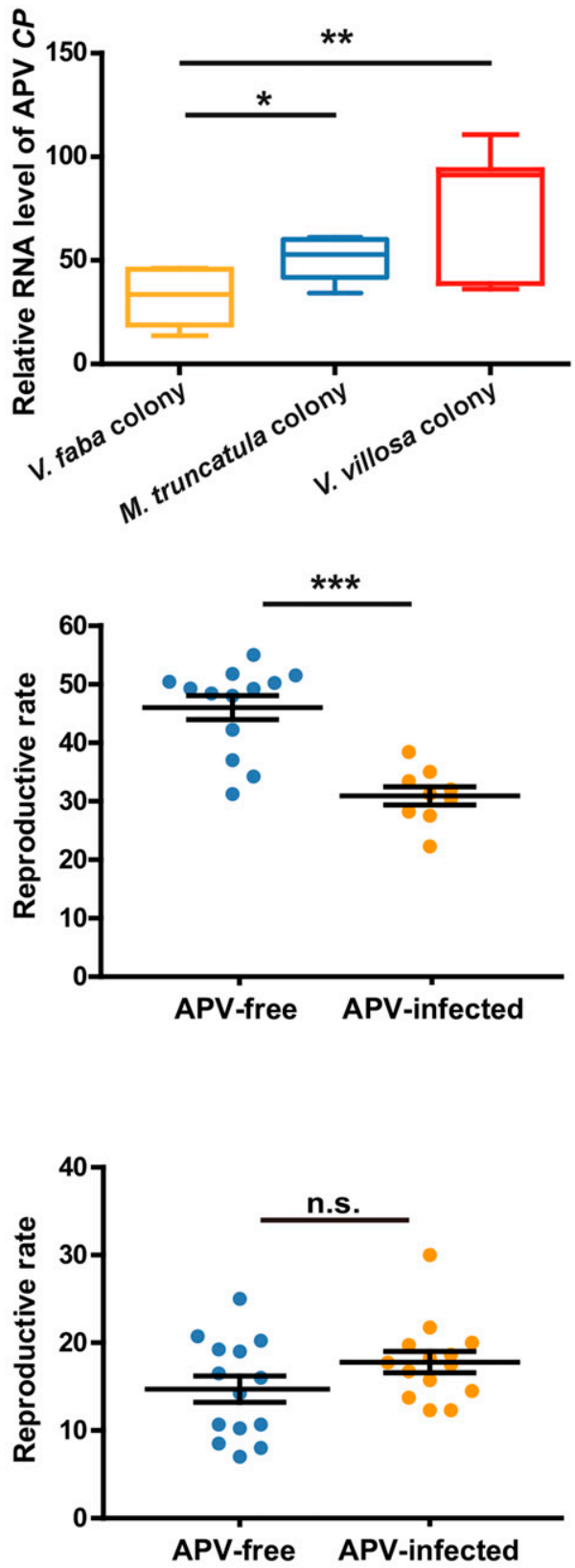

Fig. 3. Effects of acyrthosiphon pisum virus (APV) on the adaptation of aphids to a low-fitness host plant. A and B, Variation in the APV load in different aphid colonies and in Vicia faba fed on by different aphid colonies, respectively, based on reverse transcription quantitative PCR of the relative RNA levels of the APV capsid protein to those of the aphid ribosomal protein L27 or $V$. faba actin. Differences were statistically evaluated by $t$ test, using the SPSS 17.0 statistical software package. One asterisk (*) indicates $P<0.05$; two $(* *), P<0.01$; and three $(* * *), P<0.001$. Values are expressed as the mean \pm standard error (SE). At least six biological replicates were prepared. $\mathbf{C}$ and $\mathbf{D}$, Effects of APV on the survival rate and reproductive rate of pea aphids on the high-fitness host plant $V$. faba and the low-fitness host plant Vicia villosa, respectively. The survival of 60 aphids for each group was recorded every day. Cumulative survival curves for the two groups were statistically compared via the Kaplan-Meier method, using the log-rank (Mantel-Cox) test in SPSS 17.0. The reproductive rate is represented by the mean number of offspring produced by an adult in the first 5 days of the adult stage from nine to 14 biological replicates. Values are expressed as the mean \pm SE. Differences were statistically evaluated by $t$ test, using SPSS 17.0. Three asterisks $(* * *)$ indicate $P<0.001$, n.s. $=$ no significant difference. 
have been reported to be involved in aphid host adaptation by counteracting plant defense and detoxification (Bass et al. 2013; Cui et al. 2017; Hogenhout and Bos 2011). Here, we reveal a new mechanism for host adaptation of aphids through reliance on a symbiotic virus to counteract plant defense.

Aphids capitalize on the transmission mode of a symbiotic virus. Because very few APVs enter the ovaries of pea aphids, the vertical transmission rate is as low as $33 \%$. Therefore, to maintain efficient transmission between generations, APV evolved the ability to enter the salivary glands of aphids and to be secreted into host plants; in this study, APV remained in plants for at least 7 days after removal of the infected aphids. Although APV did not replicate in plants, the virus did regulate the levels of the plant hormones JA and SA in a manner that was beneficial for the host aphid. We believe that the benefit of decreased JA levels would support aphid survival on low-fitness host plants. However, based on transcriptomic and EPG analyses, APV had certain direct impacts on the aphids. Indeed, the expression levels of some genes related to detoxification and glycogen metabolism were upregulated in APV-infected aphids, and aphids harboring APV started feeding or probing sooner and had a higher abnormal stylet penetration activity compared with aphids not infected by APV. The positive function of APV in the host aphid emphasizes the evolutionary symbiosis between these two species. In addition to APV, other aphid symbiotic viruses such as rhopalosiphum padi virus, myzus persicae densovirus, dysaphis plantaginea densovirus, rosy apple aphid virus, and macrosiphum euphorbiae virus 1 were also found to have a horizontal transmission stage (Gildow and D'Arcy 1990; Ryabov et al. 2009; Teixeira et al.
A

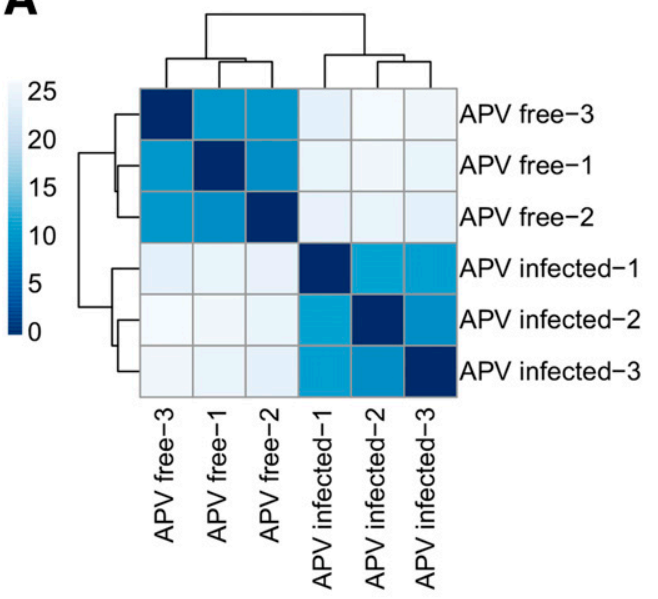

B

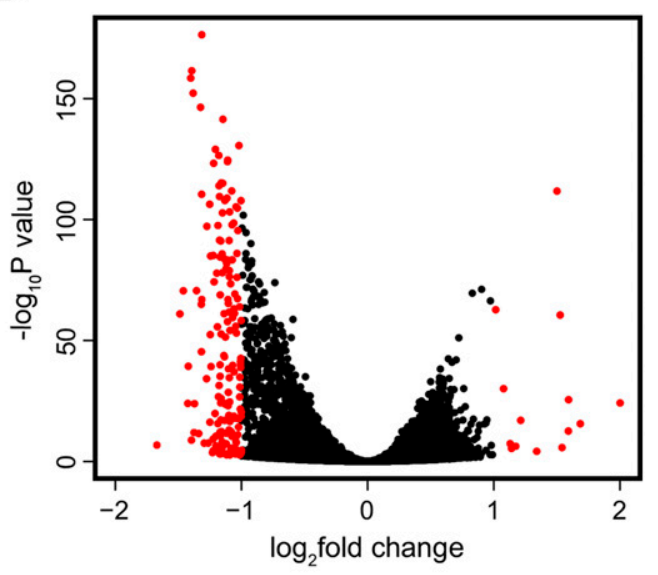

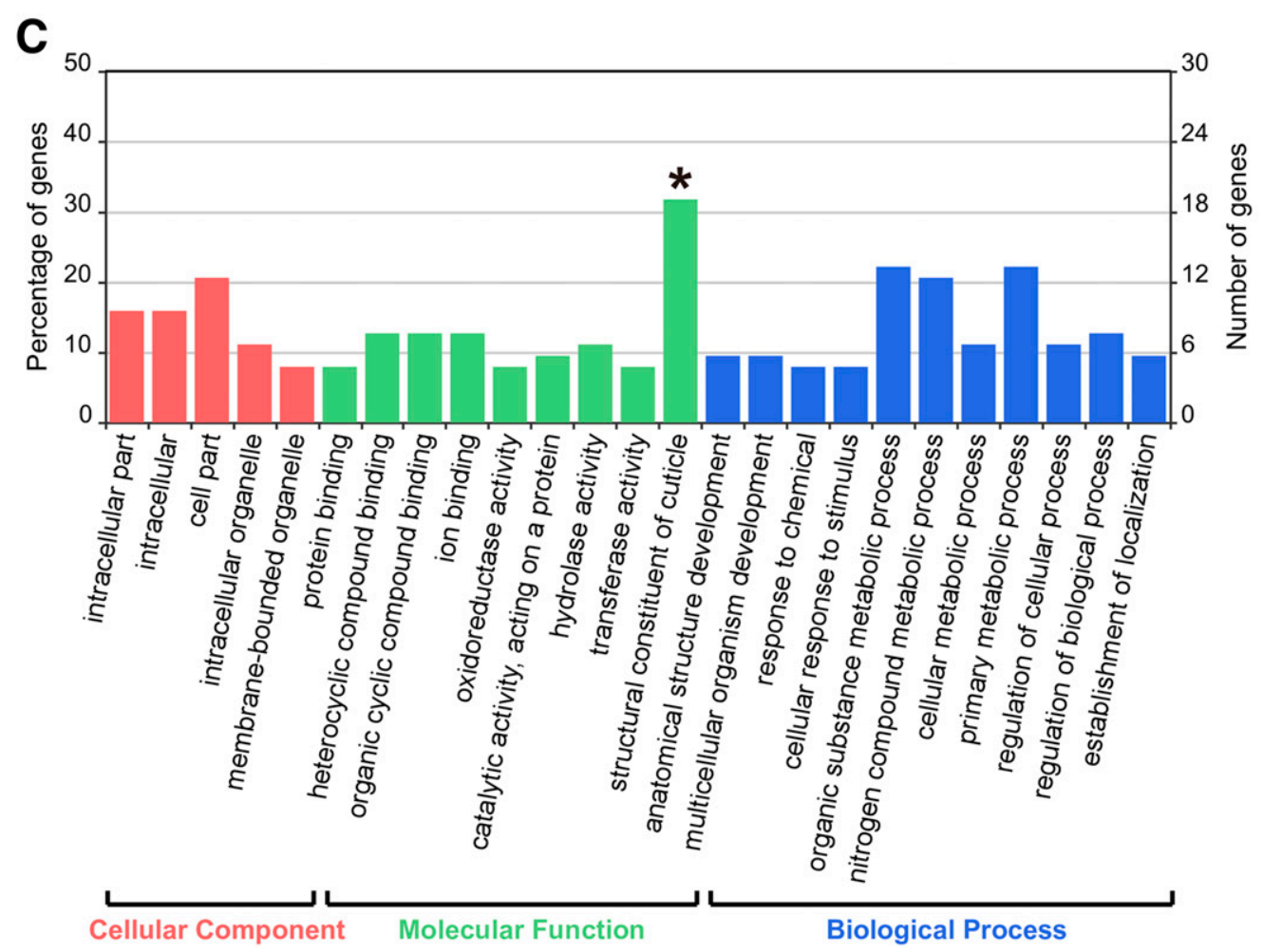

Fig. 4. Transcriptomic response of pea aphids to acyrthosiphon pisum virus (APV) infection. A, Heat map of the sample-to-sample distances of APV-infected and APV-free samples; 1,2 , and 3 represent three biological replicates. B, Volcano plot showing the differentially expressed genes (red dots) of APV-infected aphids compared with APV-free aphids (fold change $>2$ and adjusted $P$ value $<0.01$ ). C, Gene Ontology $(\mathrm{GO})$ categories in level 3 for differentially expressed genes. GO terms with at least five differentially expressed genes are shown. The black star indicates a significantly enriched GO term. 
2016; van Munster et al. 2003b). Thus, a relationship similar to that of APV and the pea aphid might exist among more pairs of symbiotic viruses and their host aphids.

APV suppressed the accumulation of JA and its derivative JA-Ile to promote the survival rate of the pea host race of aphids on the nonnative host plant $V$. villosa. JA and SA are major defense hormones in plants (Pieterse et al. 2012). JA is thought to be responsible for insect resistance, whereas SA plays a key role in pathogen resistance, though its role in resistance to piercing-sucking insects is controversial (Giordanengo et al. 2010). In most cases, the production of SA and JA is antagonistic (Walling 2008). SA accumulation, activation of SAresponsive gene expression (several pathogenesis-related, BGL, WRKY, and NPR proteins), and inhibition of JAresponsive gene expression (VSP, PDF1.2, and PI proteins) have frequently been observed in plants such as wheat, barley, tomato, and Arabidopsis thaliana after infestation with various species of aphids (Chaman et al. 2003; Cooper et al. 2004; Kerchev et al. 2013). For example, constitutive activation of JA signaling in A. thaliana enhanced resistance to Myzus persicae (Ellis et al. 2002), and blocking JA signaling promoted population growth in Myzus persicae and Brevicoryne brassicae (Mewis et al. 2006). Additionally, an effector protein, Armet, of the pea aphid induced a fourfold increase in SA accumulation; the increase in SA enhanced plant resistance to the bacterial pathogen Pseudomonas syringae but had no adverse effects on aphid survival or reproduction (Cui et al. 2019). We found that APV altered the phytohormone response toward one that was less injurious to its host aphids, allowing the aphids to survive longer and thus improving host suitability for APV. Some symbiotic bacteria have effects similar to those of APV. The Colorado potato beetle Leptinotarsa decemlineata exploits symbiotic bacteria in its oral secretions to suppress JAresponsive polyphenol oxidase activity and promote larval growth (Chung et al. 2013).

In conclusion, we discovered a positive effect of a symbiotic virus, APV, on its aphid host when the aphid population colonized host plants of low fitness. Infection by APV ensured the survival of both the virus and the host aphid during colonization of nonnative host plants through viral cross-border regulation of the phytohormone-mediated defense reaction. Recently, a similar relationship was reported for a symbiotic polydnavirus of the parasitoid Microplitis croceipes (Tan et al. 2018), whereby the virus suppressed plant-defense responses to allow the host caterpillar to grow faster. We suggest that interdependence between symbiotic viruses and host aphids may provide for the possibility of interrupting aphid host plant alterations or influencing the dispersal of aphids via manipulation of these symbiotic viruses.

\section{MATERIALS AND METHODS}

Aphids and host plants.

APV-infected pea aphids were collected from Pisum sativum (G biotype) in 2010 and were maintained on $V$. faba since (Wang et al. 2015). The V. faba colony was transferred to $V$. villosa and $M$. truncatula (A17 line) for acclimation and stable $V$. villosa and $M$. truncatula colonies were established ( $\mathrm{Lu}$ et al. 2016). The colonies were raised in growth chambers at $21 \pm 1^{\circ} \mathrm{C}$ and $60 \% \pm 5 \%$ relative humidity with a photoperiod of $16 \mathrm{~h}$ of light and $8 \mathrm{~h}$ of dark. To establish an APV-free $V$. faba colony, first-instar nymphs were collected upon hatching and were raised individually on leaves, using the Petri dish breeding method described previously (Lu et al. 2016). After the nymphs grew to adulthood and produced offspring, the adults were checked for APV using RT-PCR. Offspring of those adults with negative RT-PCR results were maintained as APV-free aphids and were reared isolated from the other colonies on $V$. faba as the stable APV-free colony.

\section{APV genome assembly.}

Six salivary gland transcriptomes of pea aphids were sequenced previously ( $\mathrm{Lu}$ et al. 2016). Reads that could not be mapped to the pea-aphid genome were mapped to the APV

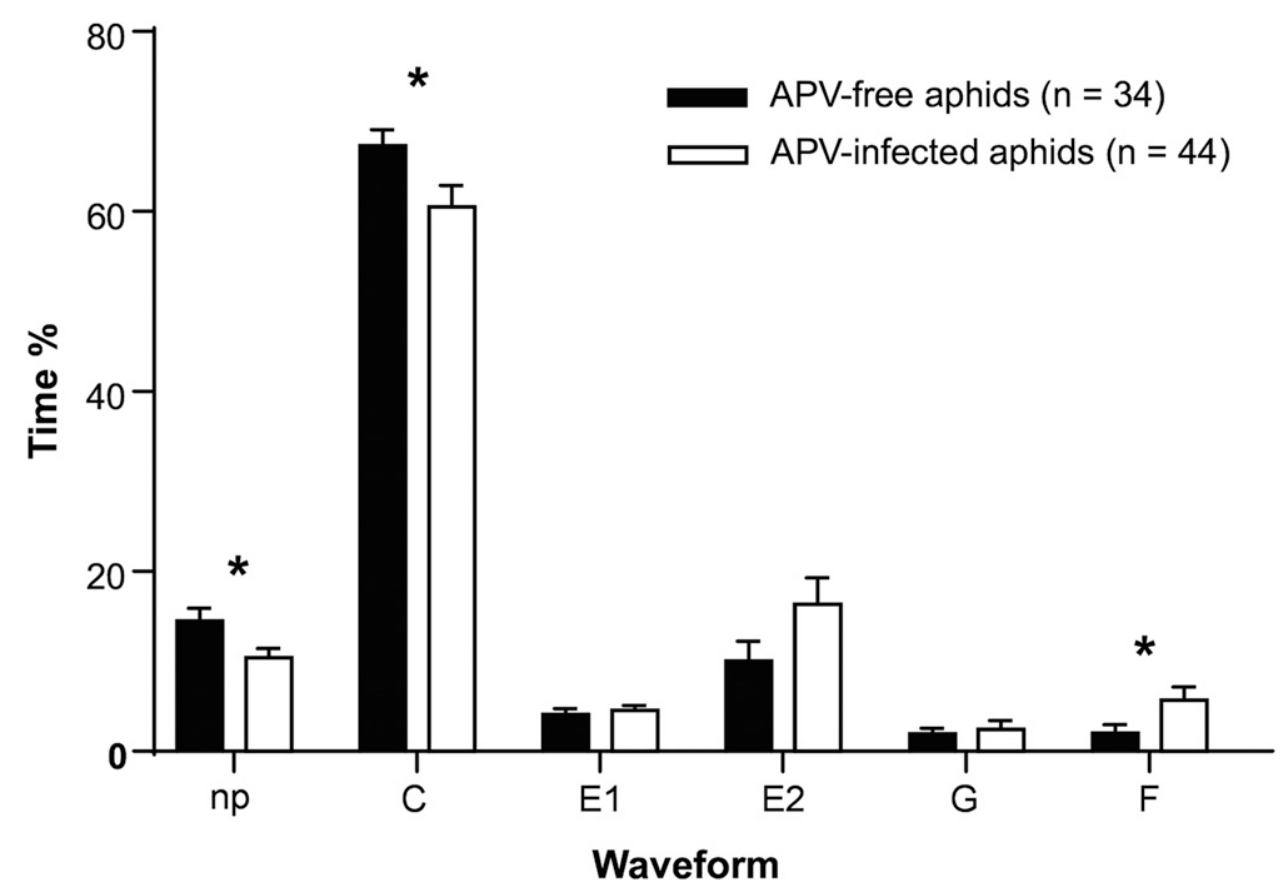

Fig. 5. Comparison of the feeding behavior of acyrthosiphon pisum virus (APV)-free and APV-infected aphids from the Vicia faba colony on Vicia villosa, using the electrical penetration graph technique. The six waveforms are nonprobing (np) and probing individual plant cells (C), watery salivation (E1), passive ingestion (E2), drinking water from xylem (G), and overcoming derailed stylet mechanics (F). The time ratio of each waveform is reported as the mean \pm standard error. Differences between the two groups were analyzed statistically by $t$ test, using SPSS 17.0 . An asterisk $(*)$ indicates $P<0.05$. 
genome (AF024514 in the National Center for Biotechnology Information [NCBI] database), using TopHat (version 2.0.12) (Kim et al. 2013) with default parameters. Trinity (version r2013-02-25) (Haas et al. 2013) was applied to assemble the sample-specific virus genome sequences with default parameters. All the assembled sequences were aligned with the reference APV genome sequence. The newly assembled APV genome sequences were registered in GenBank under accession numbers MH301282 to MH301287.

\section{APV extraction for electron microscopy observation.}

Approximately $100 \mathrm{mg}$ of aphids of the $V$. faba colony or $1 \mathrm{~g}$ of APV-infected $V$. faba was ground in liquid nitrogen and was dissolved in $700 \mu \mathrm{l}$ or $7 \mathrm{ml}$ of precooled $0.01 \mathrm{M}$ phosphate buffered saline (PBS) buffer (pH 7.2). The sample was extracted by adding half a volume of a mixture (vol/vol, 1:1) of chloroform and 1-butanol. After centrifugation at 16,000 $\times g$ for $15 \mathrm{~min}$ at $4^{\circ} \mathrm{C}$, Triton X-100, PEG 8000 and sodium chloride were added to the aqueous phase at final concentrations of $1 \%(\mathrm{vol} / \mathrm{vol}), 8 \%(\mathrm{wt} / \mathrm{vol})$ and $0.4 \mathrm{M}$, respectively. The mixture was stirred using a rotor for $1 \mathrm{~h}$, allowed to settle for $1 \mathrm{~h}$ and then centrifuged at $18,000 \times g$ for $20 \mathrm{~min}$ at $4^{\circ} \mathrm{C}$. The precipitate was resuspended in PBS buffer and was layered onto a $15 \%$ sucrose cushion. The virus was then pelleted at $31,000 \mathrm{rpm}$ for $3 \mathrm{~h}$ using a Beckman SW40Ti rotor (Beckman Coulter, Brea, CA, U.S.A.) and was resuspended in PBS buffer for electron microscopy observation, using an FEI Tecnai G2 F20 S-TWIN TMP microscope (FEI, Hillsboro, OR, U.S.A.).

RNA isolation and cDNA synthesis.

Total RNA was isolated from dissected tissues or whole bodies of aphids, using TRIzol Reagent (Invitrogen, Carlsbad,
A Vicia villosa
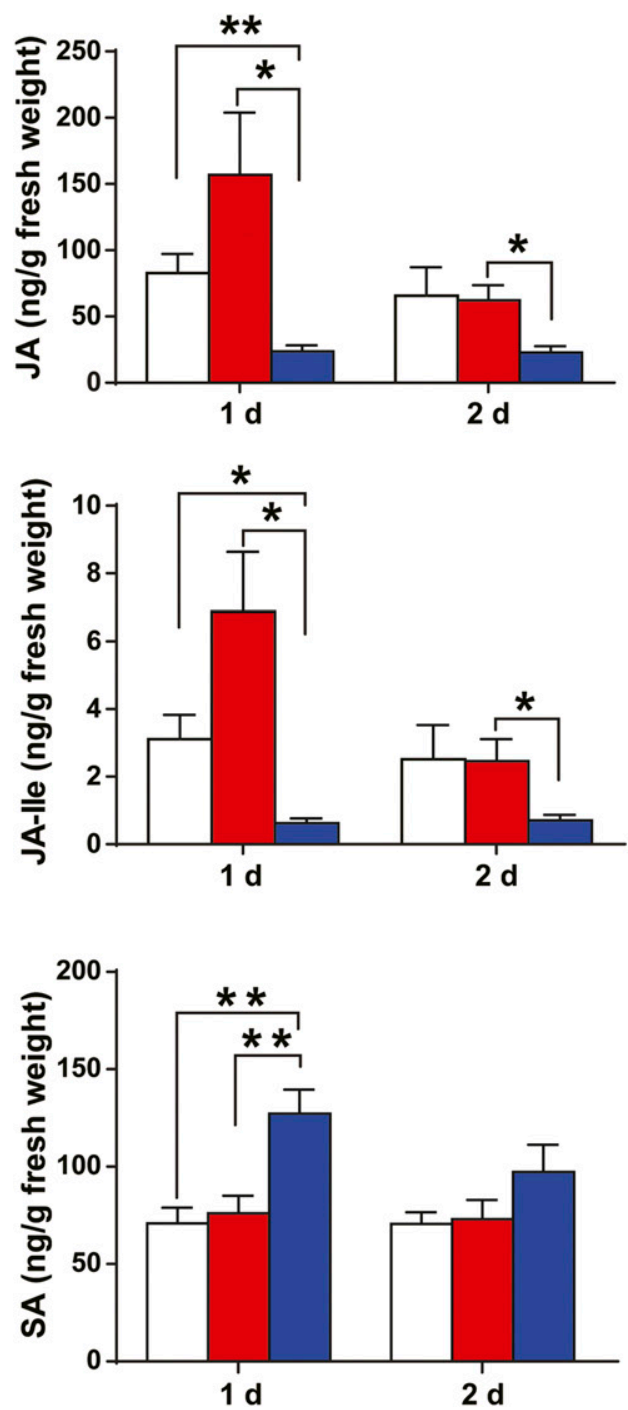

B Vicia faba
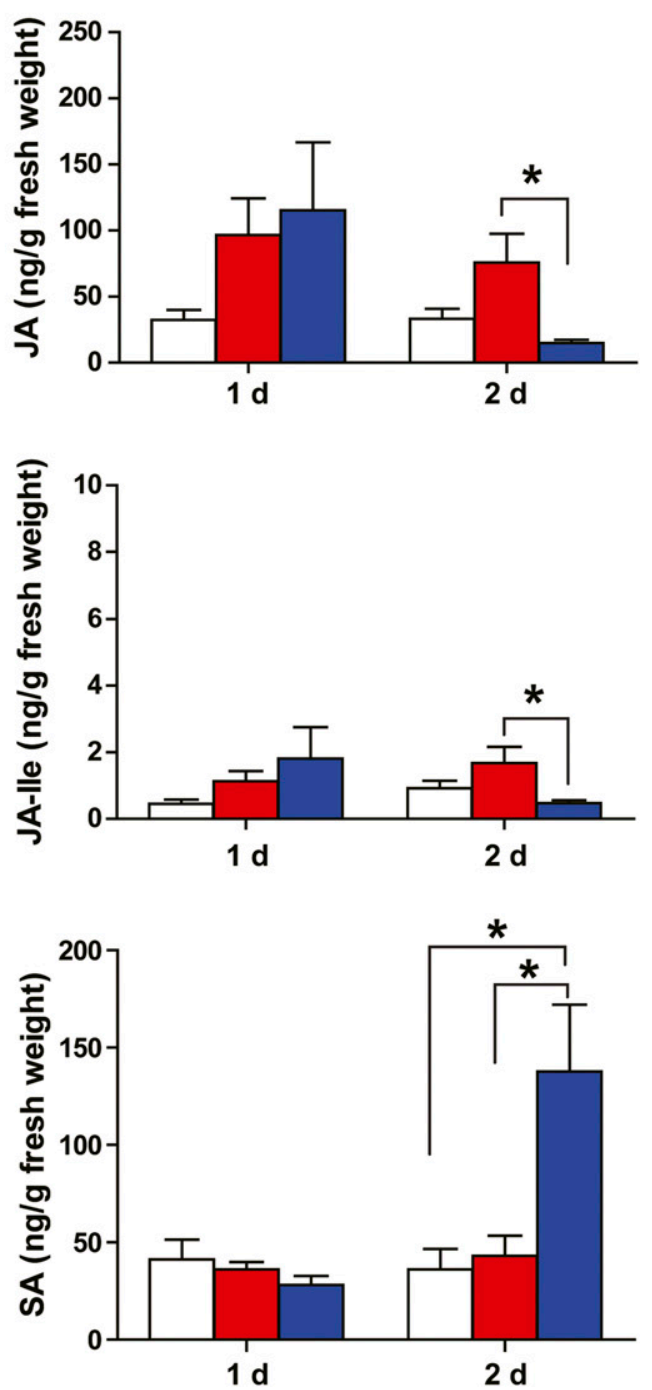

Fig. 6. Regulation of defense phytohormones in A, Vicia villosa and B, Vicia faba, respectively, by acyrthosiphon pisum virus (APV). Concentrations of jasmonic acid (JA), JA-Ile, and salicylic acid (SA) were measured and compared after infestation by APV-infected or APV-free aphids from the Vicia faba colony for 1 and 2 days or without aphid infestation. The scores are reported as the mean \pm standard error. Pairwise comparisons were analyzed statistically by $t$ test, using SPSS 17.0. One asterisk (*) indicates $P<0.05$ and two (**) indicate $P<0.01$. 
CA, U.S.A.), and from plant leaves, using an RNeasy mini kit (Qiagen, Hilden, Germany), according to manufacturer protocols. The RNA was treated with a TURBO DNA-free kit (Ambion, Austin, TX, U.S.A.) to remove genomic DNA contamination and was then reverse-transcribed to cDNA with the SuperScript III first-strand synthesis system (Invitrogen) and oligo-dT primers (Promega, Madison, WI, U.S.A.), in accordance with manufacturer instructions.

\section{RT-qPCR and RT-PCR.}

RT-qPCR was performed in $20-\mu l$ reaction mixtures, using the Roche Light Cycler 480 system (Roche, Mannheim, Germany), under thermal cycling conditions of $95^{\circ} \mathrm{C}$ for $2 \mathrm{~min}, 40$ cycles of $95^{\circ} \mathrm{C}$ for $20 \mathrm{~s}, 55^{\circ} \mathrm{C}$ for $20 \mathrm{~s}$, and $68^{\circ} \mathrm{C}$ for $20 \mathrm{~s}$, followed by one cycle of $95^{\circ} \mathrm{C}$ for $30 \mathrm{~s}, 58^{\circ} \mathrm{C}$ for $30 \mathrm{~s}$, and $95^{\circ} \mathrm{C}$ for $10 \mathrm{~s}$, to determine the melting curve. RT-PCR was performed using a Mastercycler thermal cycler (Eppendorf, Hamburg, Germany) under thermal cycling conditions of $94^{\circ} \mathrm{C}$ for $5 \mathrm{~min}$, followed by 37 cycles of $94^{\circ} \mathrm{C}$ for $30 \mathrm{~s}$, $55^{\circ} \mathrm{C}$ for $30 \mathrm{~s}$, and $72^{\circ} \mathrm{C}$ for $30 \mathrm{~s}$. PCR products were separated by $1 \%$ agarose gel electrophoresis and were viewed with the Syngene G:BOX gel imaging and analysis system (Syngene, Cambridge, U.K.) after staining with GelRed (Biotium, Hayward, CA, U.S.A.).

\section{Tissue distribution of APV in aphids.}

Four tissues (the brain, salivary gland, ovary, and gut) of adult aphids from the APV-infected $V$. faba colony were dissected in $0.9 \%$ RNA-free saline solution for RNA extraction and cDNA synthesis. Six biological replicates and 50 individuals per replicate for each tissue were prepared. The RNA level of the APV CP domain was measured by RT-qPCR with the primer pair CP-qF/CP-qR (Supplementary Table S5). The transcript level of ribosomal protein L27 (NM_001126221 in NCBI) was quantified using primer pair L27-F/L27-R as the internal control. The relative transcript level of $\mathrm{CP}$ to that of L27 is presented as the mean \pm standard error (SE). Differences were analyzed using one-way analysis of variance (ANOVA) for multiple comparisons with the SPSS 17.0 statistical software package.

\section{Vertical transmission of APV in aphids.}

A total of 52 first-instar nymphs were collected after hatching from 15 adult aphids of the APV-infected $V$. faba colony and were raised individually on a leaf, using the Petri dish breeding method described previously ( $\mathrm{Lu}$ et al. 2016). When the nymphs grew to adults, they were checked for the presence of APV using RT-PCR by amplifying the APV CP domain with primers CP-F/CP-R. Aphid actin (NM_001142636 in NCBI) was amplified using primers Apactin-F/Apactin-R as the internal control. The vertical transmission rate of APV is presented as the proportion of offspring with APV among 52 offspring.

\section{Infection of aphids with a crude preparation of APV.}

Approximately $100 \mathrm{mg}$ of aphids of the $V$. faba colony or $1 \mathrm{~g}$ of APV-infected $V$. faba was ground in liquid nitrogen and was dissolved in $700 \mu \mathrm{l}$ or $7 \mathrm{ml}$ of precooled $0.01 \mathrm{M} \mathrm{PBS}$ buffer $(\mathrm{pH}$ 7.2). After centrifugation at 2,000 $\times g$ for $5 \mathrm{~min}$ and at $5,000 \times g$ for $15 \mathrm{~min}$ at $4^{\circ} \mathrm{C}$, the supernatant containing APV was collected and was stored at $4^{\circ} \mathrm{C}$ for further use. Approximately 50 APV-free third-instar nymphs were transferred to a sterile 3.5$\mathrm{cm}$-diameter petri dish, and the dish was covered with a layer of Parafilm. APV crude preparations were mixed with an artificial diet $(15 \%$ sucrose) at a ratio of $1: 1(\mathrm{vol} / \mathrm{vol})$ and were added to the top of the Parafilm; a second layer of Parafilm was used to form a feeding sachet. After feeding on the APV crude preparations for $12 \mathrm{~h}$, the aphids were transferred to $V$. faba leaves and were raised for $0.5,1,2$, and 3 days. The RNA levels of APV CP at the four timepoints were measured by RT-qPCR with the primer pair $\mathrm{CP}-\mathrm{qF} / \mathrm{CP}-\mathrm{qR}$ to indicate the levels of virus replication in aphids. The transcript level of $\mathrm{L} 27$ was quantified using primer pair L27-F/L27-R as the internal control. At least four biological replicates and five aphids per replicate were prepared. Differences were analyzed using one-way ANOVA for multiple comparisons with the SPSS 17.0 statistical software package.

\section{Horizontal transmission of APV from aphids to plants.}

A total of 20 third-instar aphids from the APV-infected $V$. faba colony were placed on one $V$. faba leaf to feed for $48 \mathrm{~h}$ and were then removed from the leaf; $V$. faba leaves were collected at 1, 3, 5, or 7 days after aphid infestation. Another group of 20 third-instar aphids was placed on one $V$. faba leaf to feed for 1, 3, 5, or 7 days before the leaves were collected. The RNA levels of APV CP in the leaves were quantified by RTqPCR with the primer pair $\mathrm{CP}-\mathrm{qF} / \mathrm{CP}-\mathrm{qR}$. As the internal control, the transcript level of $V$. faba actin (JX444700 in NCBI) was quantified with primers Vfactin-F/Vfactin-R. The relative RNA level of $\mathrm{CP}$ is expressed as the mean $\pm \mathrm{SE}$. At least six biological replicates and two leaves per replicate were prepared. Differences were analyzed using one-way ANOVA for multiple comparisons with the SPSS 17.0 statistical software package.

\section{APV loads in different aphid colonies and in plants fed on by different aphid colonies.}

RNA levels of APV CP in adult aphids of the $V$. faba colony, $M$. truncatula colony, and $V$. villosa colony were quantified by RT-qPCR with the primer pair CP-qF/CP-qR. The transcript level of L27 was quantified using primer pair L27-F/L27-R as the internal control. At least six biological replicates and five individuals per replicate were prepared.

A total of 30 third-instar aphids from the M. truncatula or $V$. villosa colony were first transferred to $V$. faba for $24 \mathrm{~h}$ of acclimation and were then transferred to one $V$. faba leaf to feed for $48 \mathrm{~h}$. The 30 third-instar aphids from the $V$. faba colony were directly transferred to one $V$. faba leaf to feed for $48 \mathrm{~h}$. The leaves were collected for virus load measurement by quantifying the RNA levels of APV CP using RT-qPCR with the primer pair CP-qF/CP-qR. The transcript level of $V$. faba actin was determined with primers Vfactin-F/Vfactin-R as an internal control. At least six biological replicates and two leaves per replicate were prepared. Differences were analyzed using a $t$ test for pairwise comparisons with the SPSS 17.0 statistical software package.

\section{Survival curve and reproduction analysis.}

Third-instar aphids from the APV-free $V$. faba colony were fed an artificial diet (15\% sucrose) containing the APV crude preparation from the $V$. villosa colony for $12 \mathrm{~h}$, as described above, and were then raised on $V$. faba or $V$. villosa for 12 days. Aphids fed the crude extract from the APV-free $V$. faba colony were used as negative controls. Starting with 60 aphids, survival within each group was recorded every day. The survival curves of the APV-infected and control groups on V. faba or V. villosa were statistically compared via the Kaplan-Meier method using the log-rank (Mantel-Cox) test in SPSS 17.0. The number of newly hatched nymphs from five adult aphids was counted during the first 5 days of the adult stage and nine to $14 \mathrm{bi}$ ological replicates were prepared. The mean number of offspring produced by an individual was calculated and was compared between the APV-infected group and the control group on $V$. faba or $V$. villosa, using a $t$ test with SPSS 17.0. 


\section{Analysis of aphid feeding behavior.}

The EPG technique was used to analyze the feeding behavior on $V$. villosa of APV-free and APV-infected aphids from the $V$. faba colony according to a procedure previously described (Wang et al. 2015). The feeding behavior of individual fourthinstar nymphs was monitored continuously for $5 \mathrm{~h}$. Valid data sets for 34 and 44 aphids were collected for the APV-free and APV-infected groups, respectively. Six waveforms, including np, C, E1, E2, F, and G, were recorded by a Giga amplifier series GIGA-8 model (EPG-Systems, Wageningen, The Netherlands) and were analyzed with the software Stylet+. The time ratio of each waveform is reported as the mean \pm SE. Differences between the two groups were analyzed statistically by the $t$ test, using SPSS 17.0.

\section{Transcriptomic analysis of aphids.}

Third-instar aphids from the APV-free $V$. faba colony were fed an artificial diet (15\% sucrose) containing the APV crude preparation from the $V$. villosa colony for $12 \mathrm{~h}$, as described above, and were then raised on V. villosa for 8 days. Aphids fed the crude extract from the APV-free $V$. faba colony were raised on $V$. villosa for 8 days as negative controls. Total RNA from 15 aphids and three biological replicates for each treatment and control group was extracted to establish RNA-seq libraries for transcriptomic sequencing, using an Illumina Hiseq $4000 \mathrm{se}-$ quencer (Illumina, San Diego, CA, U.S.A.) with pair-end 150base pairs. Approximately $6 \mathrm{~Gb}$ and at least 40 million clean reads were obtained for each library (accession number PRJNA419454 in GenBank) and were mapped to the Acyrthosiphon pisum genome with TopHat2 (Kim et al. 2013). The number of reads mapped to each gene model was counted with HTSeq (Anders et al. 2015). DESeq2 was applied to calculate the sample-to-sample distances and to identify differentially expressed genes with a fold change $>2$ and an adjusted $P$ value $<0.01$ (Love et al. 2014). A heat map of distances was plotted using the pheatmap package in R. Functional annotations of all differentially expressed genes were assigned according to the best match derived from alignments to protein sequences in the nonredundant (NR) database using BLASTP, with a cutoff Evalue of $<10^{-5}$. Interproscan was employed to identify protein domains by searching against the Interpro (IPR) protein domain database. GO annotations were extracted from IPR entries. GO enrichment analysis for the supplied gene list was performed using BiNGO (Maere et al. 2005), a plugin in Cytoscape, with the entire annotated gene set as the background. The $P$ value was calculated using the hypergeometric test. Multiple testing correction was conducted using the Benjamini-Hochberg method (Benjamini and Hochberg 1995). GO categories of differentially expressed genes were plotted with WEGO.

\section{Measurement of SA, JA, and JA-Ile \\ in $V$. villosa and $V$. faba.}

A total of 20 third-instar aphids from the APV-infected or APV-free $V$. faba colony were transferred to six $10-\mathrm{cm}$-tall $V$. villosa seedlings or one $10-\mathrm{cm}$-tall $V$. faba seedling; the seedlings were collected after 1 or 2 days. Leaves from plants that had no aphid infestation were collected as negative controls. Five to seven replicates were prepared. Approximately $300 \mathrm{mg}$ of plant samples was ground in liquid nitrogen and was used for SA, JA, and JA-Ile measurements with a highperformance liquid chromatography-mass spectrometry system (LCMS-8040; Shimadzu Corporation, Kyoto, Japan), following a method described by (Wu et al. 2007). $\mathrm{D}_{4}-\mathrm{SA}, \mathrm{D}_{6}-\mathrm{JA}$, and ${ }^{13} \mathrm{C}_{2}$-JA-Ile were used as internal standards. The amount of each phytohormone was quantified by comparing its peak area with the peak area of the corresponding internal standard. The concentration was calculated as nanograms of phytohormone in each gram of plant fresh weight, and the result is reported as the mean \pm SE. Pairwise comparisons were analyzed statistically by $t$ test, using SPSS 17.0.

\section{LITERATURE CITED}

Anders, S., Pyl, P. T., and Huber, W. 2015. HTSeq-A Python framework to work with high-throughput sequencing data. Bioinformatics 31:166-169.

Ban, L. P., Ahmed, E., Ninkovic, V., Delp, G., and Glinwood, R. 2008. Infection with an insect virus affects olfactory behaviour and interactions with host plant and natural enemies in an aphid. Entomol. Exp. Appl. 127:108-117.

Bass, C., Zimmer, C. T., Riveron, J. M., Wilding, C. S., Wondji, C. S., Kaussmann, M., Field, L. M., Williamson, M. S., and Nauen, R. 2013. Gene amplification and microsatellite polymorphism underlie a recent insect host shift. Proc. Natl. Acad. Sci. U.S.A. 110:19460-19465.

Benjamini, Y., and Hochberg, Y. 1995. Controlling the false discovery rate: A practical and powerful approach to multiple testing. J. Roy. Stat. Soc. B Met. 57:289-300.

Blackman, R. L., and Eastop, V. F. 2000. Aphids on the World's Crops, an Identification and Information Guide. Wiley Press, Chichester, U.K.

Chaman, M. E., Copaja, S. V., and Argandoña, V. H. 2003. Relationships between salicylic acid content, phenylalanine ammonia-lyase (PAL) activity, and resistance of barley to aphid infestation. J. Agric. Food Chem. 51:2227-2231.

Chung, S. H., Rosa, C., Scully, E. D., Peiffer, M., Tooker, J. F., Hoover, K., Luthe, D. S., and Felton, G. W. 2013. Herbivore exploits orally secreted bacteria to suppress plant defenses. Proc. Natl. Acad. Sci. U.S.A. 110:15728-15733.

Cooper, W. C., Jia, L., and Goggin, F. L. 2004. Acquired and $R$ gene-mediated resistance against the potato aphid in tomato. J. Chem. Ecol. 30:2527-2542.

Cui N, Lu H, Wang T, Zhang W, Kang L, Cui F. 2019. Armet, an aphid effector protein, induces pathogen resistance in plants by promoting the accumulation of salicylic acid. Philos Trans R Soc Lond Ser B Biol Sci. 374: 20180314.

Cui, N., Yang, P. C., Guo, K., Kang, L., and Cui, F. 2017. Large-scale gene expression reveals different adaptations of Hyalopterus persikonus to winter and summer host plants. Insect Sci. 24:431-442.

Douglas, A. E. 2013. Microbial brokers of insect-plant interactions revisited. J. Chem. Ecol. 39:952-961.

Ellis, C., Karafyllidis, I., and Turner, J. G. 2002. Constitutive activation of jasmonate signaling in an Arabidopsis mutant correlates with enhanced resistance to Erysiphe cichoracearum, Pseudomonas syringae, and Myzus persicae. Mol. Plant-Microbe Interact. 15:1025-1030.

Ferrari, J., Godfray, H. C., Faulconbridge, A. S., Prior, K., and Via, S. 2006. Population differentiation and genetic variation in host choice among pea aphids from eight host plant genera. Evolution 60:1574-1584.

Gildow, F. E., and D'Arcy, C. J. 1990. Cytopathology and experimental host range of Rhopalosiphum padi virus, a small isometric RNA virus infecting cereal grain aphids. J. Invertebr. Pathol. 55:245-257.

Giordanengo, P., Brunissen, L., Rusterucci, C., Vincent, C., van Bel, A., Dinant, S., Girousse, C., Faucher, M., and Bonnemain, J. L. 2010. Compatible plant-aphid interactions: How aphids manipulate plant responses. C. R. Biol. 333:516-523.

Haas, B. J., Papanicolaou, A., Yassour, M., Grabherr, M., Blood, P. D., Bowden, J., Couger, M. B., Eccles, D., Li, B., Lieber, M., MacManes, M. D., Ott, M., Orvis, J., Pochet, N., Strozzi, F., Weeks, N., Westerman, R., William, T., Dewey, C. N., Henschel, R., LeDuc, R. D., Friedman, N., and Regev, A. 2013. De novo transcript sequence reconstruction from RNA-seq using the Trinity platform for reference generation and analysis. Nat. Protoc. 8:1494-1512.

Hogenhout, S. A., and Bos, J. I. 2011. Effector proteins that modulate plant-Insect interactions. Curr. Opin. Plant Biol. 14:422-428.

Hogenhout, S. A., Van der Hoorn, R. A., Terauchi, R., and Kamoun, S. 2009. Emerging concepts in effector biology of plant-associated organisms. Mol. Plant-Microbe Interact. 22:115-122.

Kerchev, P. I., Karpińska, B., Morris, J. A., Hussain, A., Verrall, S. R., Hedley, P. E., Fenton, B., Foyer, C. H., and Hancock, R. D. 2013. Vitamin $\mathrm{C}$ and the abscisic acid-insensitive 4 transcription factor are important determinants of aphid resistance in Arabidopsis. Antioxid. Redox Signal. 18:2091-2105.

Kim, D., Pertea, G., Trapnell, C., Pimentel, H., Kelley, R., and Salzberg, S. L. 2013. TopHat2: Accurate alignment of transcriptomes in the presence of insertions, deletions and gene fusions. Genome Biol. 14:R36.

Liu, S., Vijayendran, D., Chen, Y., and Bonning, B. C. 2016. Aphis glycines virus 2, a novel insect virus with a unique genome structure. Viruses 8: 315. 
Love, M. I., Huber, W., and Anders, S. 2014. Moderated estimation of fold change and dispersion for RNA-seq data with DESeq2. Genome Biol. 15:550.

Lu, H., Yang, P., Xu, Y., Luo, L., Zhu, J., Cui, N., Kang, L., and Cui, F. 2016. Performances of survival, feeding behavior, and gene expression in aphids reveal their different fitness to host alteration. Sci. Rep. 6:19344.

Maere, S., Heymans, K., and Kuiper, M. 2005. BiNGO: A Cytoscape plugin to assess overrepresentation of gene ontology categories in biological networks. Bioinformatics 21:3448-3449.

Mewis, I., Tokuhisa, J. G., Schultz, J. C., Appel, H. M., Ulrichs, C., and Gershenzon, J. 2006. Gene expression and glucosinolate accumulation in Arabidopsis thaliana in response to generalist and specialist herbivores of different feeding guilds and the role of defense signaling pathways. Phytochemistry 67:2450-2462.

Montllor, C. B., Maxmen, A., and Purcell, A. H. 2002. Facultative bacterial endosymbionts benefit pea aphids Acyrthosiphon pisum under heat stress. Ecol. Entomol. 27:189-195.

Moon, J. S., Domier, L. L., McCoppin, N. K., D’Arcy, C. J., and Jin, H. 1998. Nucleotide sequence analysis shows that Rhopalosiphum padi virus is a member of a novel group of insect-infecting RNA viruses. Virology 243:54-65.

Moran, N. A. 1992. The evolution of aphid life cycles. Annu. Rev. Entomol. 37:321-348.

Peccoud, J., Ollivier, A., Plantegenest, M., and Simon, J. C. 2009. A continuum of genetic divergence from sympatric host races to species in the pea aphid complex. Proc. Natl. Acad. Sci. U.S.A. 106:7495-7500.

Pieterse, C. M. J., Van der Does, D., Zamioudis, C., Leon-Reyes, A., and Van Wees, S. C. M. 2012. Hormonal modulation of plant immunity. Annu. Rev. Cell Dev. Biol. 28:489-521.

Ryabov, E. V. 2007. A novel virus isolated from the aphid Brevicoryne brassicae with similarity to Hymenoptera picorna-like viruses. J. Gen. Virol. 88:2590-2595.

Ryabov, E. V., Keane, G., Naish, N., Evered, C., and Winstanley, D. 2009. Densovirus induces winged morphs in asexual clones of the rosy apple aphid, Dysaphis plantaginea. Proc. Natl. Acad. Sci. U.S.A. 106:8465-8470.

Scarborough, C. L., Ferrari, J., and Godfray, H. C. J. 2005. Aphid protected from pathogen by endosymbiont. Science 310:1781.
Tan, C. W., Peiffer, M., Hoover, K., Rosa, C., Acevedo, F. E., and Felton, G. W. 2018. Symbiotic polydnavirus of a parasite manipulates caterpillar and plant immunity. Proc. Natl. Acad. Sci. U.S.A. 115:5199-5204.

Teixeira, M., Sela, N., Ng, J., Casteel, C. L., Peng, H. C., Bekal, S., Girke, T., Ghanim, M., and Kaloshian, I. 2016. A novel virus from Macrosiphum euphorbiae with similarities to members of the family Flaviviridae. J. Gen. Virol. 97:1261-1271.

Tsuchida, T., Koga, R., Horikawa, M., Tsunoda, T., Maoka, T., Matsumoto, S., Simon, J. C., and Fukatsu, T. 2010. Symbiotic bacterium modifies aphid body color. Science 330:1102-1104.

van den Heuvel, J. F. J. M., Hummelen, H., Verbeek, M., Dullemans, A. M., and van der Wilk, F. 1997. Characteristics of acyrthosiphon pisum virus, a newly identified virus infecting the pea aphid. J. Invertebr. Pathol. 70: $169-176$.

van der Wilk, F., Dullemans, A. M., Verbeek, M., and Van den Heuvel, J. F. J. M. 1997. Nucleotide sequence and genomic organization of Acyrthosiphon pisum virus. Virology 238:353-362.

van Munster, M., Dullemans, A. M., Verbeek, M., van den Heuvel, J. F. J. M., Reinbold, C., Brault, V., Clérivet, A., and van der Wilk, F. 2003a. A new virus infecting Myzus persicae has a genome organization similar to the species of the genus Densovirus. J. Gen. Virol. 84:165-172.

van Munster, M., Dullemans, A. M., Verbeek, M., van den Heuvel, J. F. J. M., Reinbold, C., Brault, V., Clérivet, A., and van der Wilk, F. 2003b. Characterization of a new densovirus infecting the green peach aphid Myzus persicae. J. Invertebr. Pathol. 84:6-14.

Vorburger, C. 2014. The evolutionary ecology of symbiont-conferred resistance to parasitoids in aphids. Insect Sci. 21:251-264.

Walling, L. L. 2008. Avoiding effective defenses: Strategies employed by phloem-feeding insects. Plant Physiol. 146:859-866.

Wang, W., Dai, H., Zhang, Y., Chandrasekar, R., Luo, L., Hiromasa, Y., Sheng, C., Peng, G., Chen, S., Tomich, J. M., Reese, J., Edwards, O., Kang, L., Reeck, G., and Cui, F. 2015. Armet is an effector protein mediating aphid-plant interactions. FASEB J. 29:2032-2045.

Wu, J., Hettenhausen, C., Meldau, S., and Baldwin, I. T. 2007. Herbivory rapidly activates MAPK signaling in attacked and unattacked leaf regions but not between leaves of Nicotiana attenuata. Plant Cell 19: 1096-1122. 